\title{
Multisensory Spatial Attention Deficits Are Predictive of Phonological Decoding Skills in Developmental Dyslexia
}

\author{
Andrea Facoetti ${ }^{1,2}$, Anna Noemi Trussardi ${ }^{1,3}$, Milena Ruffino ${ }^{1,2}$, \\ Maria Luisa Lorusso ${ }^{2}$, Carmen Cattaneo ${ }^{2}$, Raffaella Galli ${ }^{2}$, \\ Massimo Molteni ${ }^{2}$, and Marco Zorzi ${ }^{1}$
}

\begin{abstract}
Although the dominant approach posits that developmental dyslexia arises from deficits in systems that are exclusively linguistic in nature (i.e., phonological deficit theory), dyslexics show a variety of lower level deficits in sensory and attentional processing. Although their link to the reading disorder remains contentious, recent empirical and computational studies suggest that spatial attention plays an important role in phonological decoding. The present behavioral study investigated exogenous spatial attention in dyslexic children and matched controls by measuring RTs to visual and auditory stimuli in cued-detection tasks. Dyslexics with poor nonword decoding accuracy showed a slower time course of visual and auditory (multisensory) spatial
\end{abstract}

\section{INTRODUCTION}

Developmental dyslexia (DD) is defined as a neurobiological deficit in reading acquisition despite normal intelligence and access to conventional instruction (American Psychiatric Association, 1994). Models of reading aloud (Perry, Ziegler, \& Zorzi, 2007; Coltheart, Rastle, Perry, Langdon, \& Ziegler, 2001; Harm \& Seidenberg, 1999; Zorzi, Houghton, \& Butterworth, 1998a) converge in the assumption that oral reading involves the interaction between two different routes or networks that produce lexical-semantic and sublexical phonological information, respectively (for a review, see Zorzi, 2005). The latter allows readers to read unfamiliar words and nonwords. A particular difficulty in reading this type of stimuli is the hallmark of phonological dyslexia, which is generally thought to reflect impaired sublexical and/or phonological processing (Bosse, Tainturier, \& Valdois, 2007; Manis, Seidemberg, Doi, McBride-Chang, \& Petersen, 2000; Castles \& Coltheart, 1993).

Phonological decoding, which is typically measured by examining children's nonword reading performance, is one of the most critical skills for successful reading acquisi-

${ }^{1}$ Università di Padova, Italy, ${ }^{2}$ Istituto Scientifico "E. Medea" di Bosisio Parini, Lecco, Italy, ${ }^{3}$ Azienda Ospedaliera di Bergamo, Italy attention compared with both chronological age and reading level controls as well as compared with dyslexics with slow but accurate nonword decoding. Individual differences in the time course of multisensory spatial attention accounted for $31 \%$ of unique variance in the nonword reading performance of the entire dyslexic sample after controlling for age, IQ, and phonological skills. The present study suggests that multisensory "sluggish attention shifting"-related to a temporoparietal dysfunction-selectively impairs the sublexical mechanisms that are critical for reading development. These findings may offer a new approach for early identification and remediation of developmental dyslexia. tion (Ziegler \& Goswami, 2005; Share, 1995; for a computational study, see Zorzi, Houghton, \& Butterworth, 1998b). Nonword reading is a crucial skill because it allows children to make the connection between novel letter sequences and words that are already stored in their phonological (spoken word) lexicon. It is this ability to generalize (i.e., to assemble a phonological code for any string of letters) that allows the child to successfully decode and construct orthographic entries for thousands of new words during the first years of education (Share, 1995). Accordingly, most longitudinal studies have shown that beginning readers use primarily the sublexical route both for reading aloud and for silent reading (for a review, see SprengerCharolles, Siegel, Béchennec, \& Serniclaes, 2003). Conversely, nonword reading skills (in terms of both speed and accuracy) are consistently impaired in dyslexic children across different languages (Ziegler, Perry, Wyatt, Ladner, \& Schülte-Korne, 2003).

Phonological decoding (but not lexical processing) is an attention-demanding process even in skilled adult readers (Reynolds \& Besner, 2006). In particular, graphemic parsing, that is, the segmentation of a letter string into its constituent graphemes (Perry et al., 2007), requires an efficient orienting of visual spatial attention (Perry et al., 2007; Facoetti et al., 2006; Cestnick \& Coltheart, 1999) 
in addition to appropriate phonological skills (Ziegler \& Goswami, 2005; Ramus, 2003). Notably, impaired visual spatial attention has been repeatedly described in DD (e.g., Bosse et al., 2007; Facoetti et al., 2006; Facoetti, Lorusso, Cattaneo, Galli, \& Molteni, 2005; Cestnick \& Coltheart, 1999; for a review, see Hari \& Renvall, 2001) and more specifically in dyslexics with poor nonword reading ability (Jones, Branigan, \& Kelly, 2008; Roach \& Hogben, 2007; Facoetti et al., 2006; Buchholz \& McKone, 2004; Cestnick \& Coltheart, 1999).

Spatial attention is known to enhance the neural representation of the attended stimuli (for a review, see Reynolds \& Chelazzi, 2004), and it has been shown to modulate even the earliest sensory processing in the primary visual and auditory cortices (Poghosyan \& Ioannides, 2008). For example, spatial attention improves perception in many visual tasks, such as contrast sensitivity, texture segmentation, and visual search, by diminishing the effect of noise outside the focus of attention, intensifying the signal, and enhancing spatial resolution (Carrasco, Williams, \& Yeshurum, 2002). It allows decisions to be based on the selected stimulus alone, disregarding distracting stimuli by perceptual noise exclusion (Dosher \& Lu, 2000).

Converging evidence for the hypothesis that a visual spatial attentional deficit could specifically impair sublexical processing in DD comes from studies, suggesting that visual spatial attention is more important for nonword reading than for word reading. For instance, a manipulation of visual attention using spatial cues makes skilled adult readers more inaccurate in reporting the letters from the unattended side of nonwords as compared with words (Auclair \& Sieroff, 2002). Moreover, neurological patients with hemispatial neglect (i.e., a deficit of spatial attention following parietal lesions) make more errors on the contralesional side of nonwords compared with words (Sieroff, Pollatsek, \& Posner, 1988). However, patients with severe neglect dyslexia show preserved lexical-semantic processing in reading (Ladavas, Umiltà, \& Mapelli, 1997), suggesting an interaction between the visual spatial attentional system and the different reading routes. Notably, a recent computational model of reading aloud (Perry et al., 2007) assumes that focused spatial attention is selectively involved in the sublexical processing of orthographic material (see also Ans, Carbonnel, \& Valdois, 1998).

Efficient learning of sublexical spelling-sound mappings requires not only graphemic parsing but also accurate representations at the phoneme level (Perry et al., 2007; Ziegler \& Goswami, 2005; Harm \& Seidenberg, 1999). Indeed, several authors argued that the core problem in DD is a deficit in phonological representation (for a review, see Ramus, 2003). In fact, it is possible that a low-level auditory processing deficit in DD impairs speech perception (for a review, see Tallal, 2004) and more specifically its sublexical processing (which in turn would affect grapheme-phoneme conversion and phonological shortterm memory). Accordingly, Goswami et al. (2000) reported that children with DD are relatively insensitive to the rise times of amplitude envelope onsets in acoustic signals in comparison to normally reading children. The ability to detect this feature of the acoustic signal provides a non-speech-specific mechanism for segmenting syllable onsets and rimes, which in turn is a crucial precursor to the development of phoneme segmentation skills (Goswami et al., 2000).

However, it is important to note that efficient acoustic processing and segmentation of the speech signal are likely to require the rapid engagement of auditory attention (Facoetti et al., 2005; Renvall \& Hari, 2002). Indeed, auditory attention is necessary for speech segmentation based on statistical learning (Toro, Sinnett, \& Soto-Faraco, 2005) and for learning phonetic discriminations based on acoustic cues (Francis, Kaganovich, \& Criscoll-Huber, 2008; Gordon, Eberhardt, \& Rueckl, 1993). Moreover, auditory spatial attention has been shown to be defective in children with specific language impairment (SLI; Stevens, Sanders, \& Neville, 2006) or reading disorders (Asbjørnsen \& Bryden, 1998).

The present study is motivated by the hypothesis that a multisensory (i.e., visual and auditory) deficit of spatial attention in DD (cf. "sluggish attention shifting"; Hari \& Renvall, 2001) provides a unitary framework that is coherent with the recent proposal of perceptual noise exclusion deficit in dyslexia (e.g., Geiger et al., 2008; Sperling, Lu, Manis, \& Seidemberg, 2005) and offers a much more plausible account than a single deficit in the visual-orthographic or auditory-phonological processing domain (e.g., Ramus, 2003). A multisensory deficit of spatial attention would have a detrimental effect on the process of segmenting into components both the auditory signals (i.e., speech) and the visual input (i.e., letter strings). Computational studies have clearly shown that phonological assembly relies on the efficient parsing into grapheme and phoneme units (Perry et al., 2007; Hutzler, Ziegler, Perry, Wimmer, \& Zorzi, 2004).

Neuroimaging studies of both typical and atypical reading development have consistently implicated regions that are known to subserve the orienting of attention (for a review of the functional anatomy of attention, see Corbetta \& Shulman, 2002). For example, several studies using phonological tasks have shown deficient task-related activation in areas surrounding the bilateral TPJ in dyslexics (for a review, see Eden \& Zeffiro, 1998). Although the left TPJ has been linked to auditory-phonological processing (for a review, see Pugh et al., 2000), the right TPJ is a crucial component of the network subserving stimulus-driven orienting of attention (Corbetta \& Shulman, 2002). Notably, developmental changes in right TPJ activation have been linked to reading acquisition in normally developing children (Hoeft et al., 2006; Turkeltaub, Gareau, Flowers, Zeffiro, \& Eden, 2003), and some studies have observed a right TPJ deficiency in dyslexics (e.g., Hoeft et al., 2006; Grünling et al., 2004; Rumsey et al., 1997). More generally, it is likely that the attention network exerts modulatory influences on both visual-orthographic processing in the 
occipitotemporal areas (for a review, see McCandliss, Cohen, \& Dehaene, 2003) and auditory-phonological processing in the left TPJ.

A relationship between impaired spatial attention and nonword reading in DD was already described in one of our previous studies (Facoetti et al., 2006). The ability to orient visual attention in the right visual field correlated with nonword reading accuracy in a sample of 33 dyslexic children. However, further investigation of these findings is motivated by a number of critical issues. First, the former study investigated only visual spatial attention, whereas the present study included both visual and auditory attention. Second, the former study did not investigate the time course of attention; indeed, the failure in orienting visual attention reported by Facoetti et al. (2006) might be explained by an abnormal time course rather than by an orienting deficit per se. Third, the spatial cueing paradigm used by Facoetti et al. used both central and peripheral informative visual arrows as cuestherefore mixing endogenous, exogenous, and reflexive attention (for a discussion, see Bonato, Priftis, Marenzi, \& Zorzi, 2009)—whereas the present study used only peripheral noninformative cues to isolate stimulus-driven (i.e., exogenous) multisensory spatial attention. Fourth, the present study included a control group matched to the dyslexic group for reading level (see Goswami, 2003), whereas the former study had only controls matched for chronological age. The latter point is particularly important to address the issue of the direction of the link between spatial attention deficit and poor phonological decoding (see Discussion section).

We measured the time course of visual and auditory exogenous spatial attention (ESA) in dyslexic children and two groups of controls, one matched for chronological age and the other for reading level. ESA is typically investigated with a spatial cueing procedure (Posner, 1980), in which attention is engaged across locations (without eye movements) by a peripheral and an uninformative spatial cue (i.e., cue location does not predict target location). The cue is valid when the target appears at the cued location, whereas it is invalid when the target appears at the uncued location (see Figure 1). Faster RTs in the valid compared with the invalid condition (i.e., the cueing effect) indicate that ESA has been efficiently engaged (i.e., processing at attended location has been enhanced and processing at unattended location has been suppressed). Note that processing facilitation in ESA is usually found at short cue-target delays only (e.g., 50-150 msec; for a review, see Klein, 2000). Therefore, a sluggish ESA might be revealed by an offset of the normal time course of the cueing effect. Moreover, we investigated the predictive value of ESA with respect to nonword and word reading in dyslexic children. If multisensory ESA is a low-level nonspeech mechanism involved in sublexical processing, then measures of ESA should predict nonword reading even when age, IQ, and phonological skills are controlled for.

\section{METHODS}

\section{Participants}

Visual and auditory spatial attention was studied in 22 Italian DD children (16 boys and 6 girls) and in 31 control children (13 boys and 18 girls) without reading difficulties. DD children were recruited at the Developmental Neuropsychology Unit of a Research Hospital in northern Italy (IRCCS "E Medea," Bosisio Parini, Lecco) and had been diagnosed as dyslexics based on standard exclusion criteria (American Psychiatric Association, 1994). They were between 8 and 13 years old (mean age $=10.75$ years, $S D=1.53$ years), and their performance (accuracy and/ or speed) in reading was $2 S D$ s below the norm on at least one of the age-standardized Italian tests included in the battery (text reading, Cornoldi, Colpo, \& Gruppo, 1981; single word and nonword reading, Sartori, Job, \& Tressoldi, 1995). DD participants were selected based on (a) a full-scale IQ greater than 85 , as measured by the Wechsler Intelligence Scale for Children-Revised (WISC-R; Wechsler, 1986); (b) a normal or corrected-to-normal vision and hearing; (c) the absence of neurological and/or psychiatric disorders; and (d) the absence of attention deficit disorder with hyperactivity or SLI (because of their high comorbidity with DD), as evaluated through Diagnostic and Statistical Manual of Mental Disorders, Fourth Edition diagnostic criteria (American Psychiatric Association, 1994).

The ability to read aloud single words and nonwords was measured on a standardized list of 102 Italian words and 48 Italian nonwords (Sartori et al., 1995). Norms are available for both accuracy and fluency. The latter is measured by total time (sec) spent on a specific list. Dyslexic children were divided into two groups based on their accuracy in nonword decoding (see Table 1). As in the study of Facoetti et al. (2006), a dyslexic child was assigned to the DDN - group (where $\mathrm{N}-$ indicates poor nonword reading) if her $Z$ score for nonword reading accuracy was below 1.5 SDs on the standardized list of nonwords. All dyslexic children who did not meet the criterion for inclusion in the DDN - group were assigned to the DDN+ group (where $\mathrm{N}+$ indicates near-normal nonword reading). The mean $Z$ score for nonword reading accuracy was -3.1 for the DDN - group and -0.7 for the DDN+ group, $t(20)=5.15, p<.0001$. Note that nonword reading accuracy is the most appropriate measure of phonological decoding skills-thus, a performance well below the normative data implies that the child is a poor phonological decoder. Of course this does not mean that word reading is normal-a dissociation would be surprising in a shallow orthography like Italian. Indeed, the mean $Z$ score for DDN- was below -3 for both word and nonword reading accuracy. In contrast, children assigned to the DDN+ group showed a marked fluency deficit, but their decoding was accurate. ${ }^{1}$ That is, their reading accuracy was close to normal, but their speed was more than 3 SDs below the norm both for words and nonwords. 
A

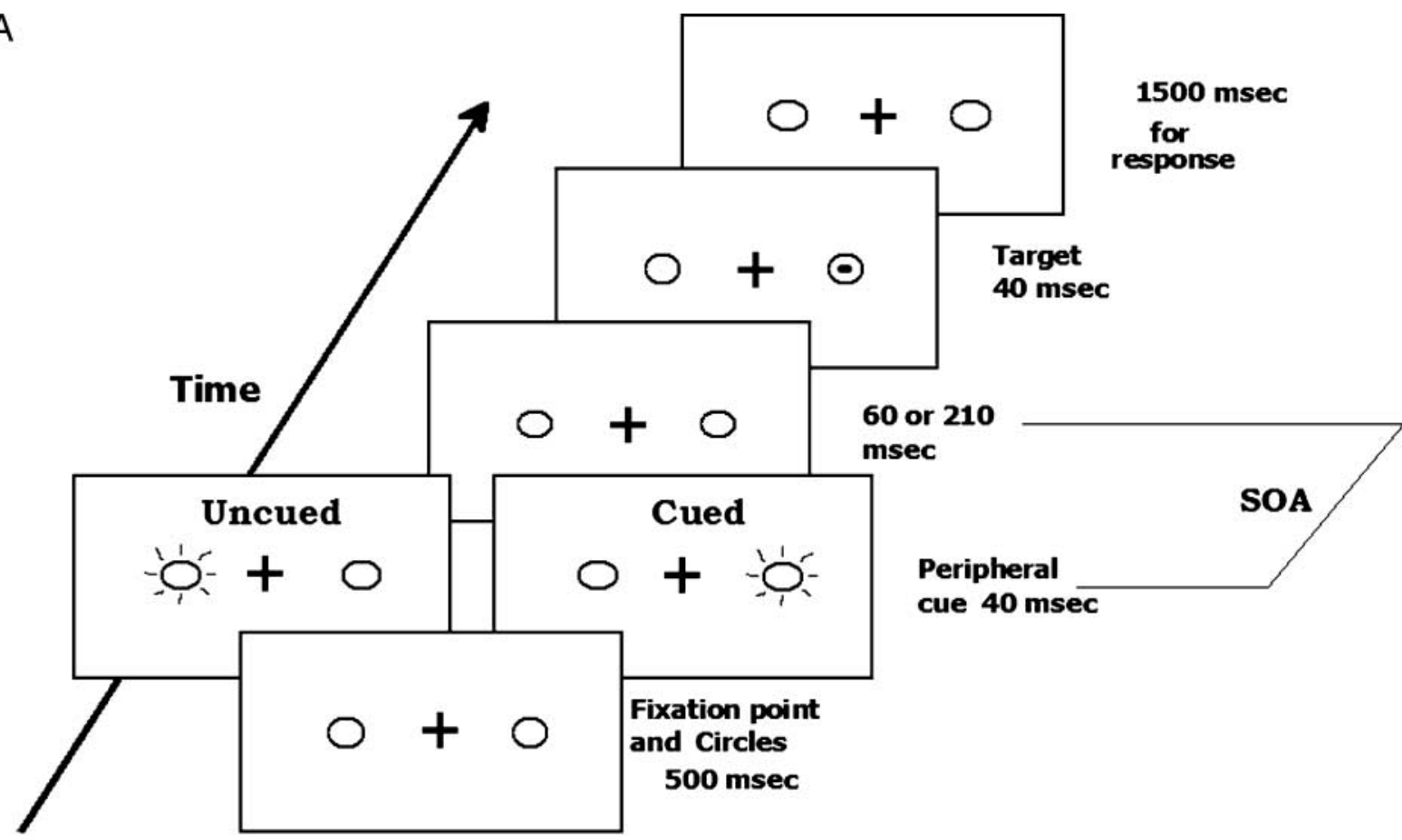

B

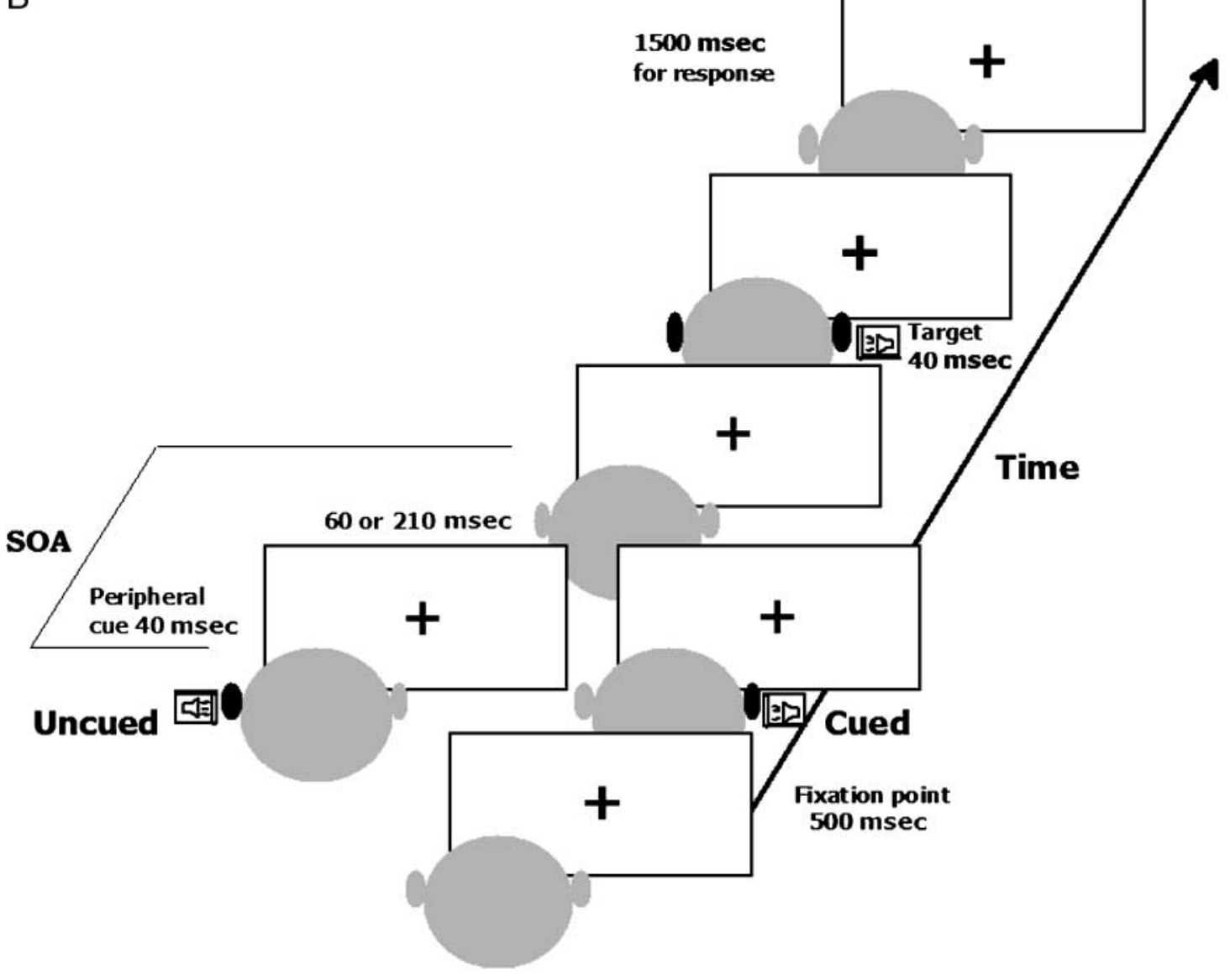

Figure 1. Schematic representation of the display used in the (A) visual and (B) auditory spatial cued-detection tasks. 
Table 1. Characteristics of Two Groups of Dyslexic Children

\begin{tabular}{|c|c|c|c|c|c|c|}
\hline & \multicolumn{2}{|c|}{$D D N-(n=13)$} & \multicolumn{2}{|c|}{$D D N+(n=9)$} & \multicolumn{2}{|c|}{ Comparison } \\
\hline & $M$ & $S D$ & $M$ & $S D$ & $t(20)$ & $p$ \\
\hline Age & 11.06 & 1.41 & 10.31 & 1.67 & 1.1 & .29 \\
\hline Global IQ & 98.2 & 7.7 & 101.3 & 7.01 & 0.97 & .34 \\
\hline Nonword reading accuracy & -3.1 & 1.48 & -.7 & .66 & -5.15 & $<.0001$ \\
\hline Nonword reading speed & -3.01 & 1.22 & -3.24 & 2.39 & 0.16 & .87 \\
\hline Word reading accuracy & -3.69 & 2.85 & -1.07 & 1.1 & 2.68 & $<.05$ \\
\hline Word reading speed & -4.48 & 2.86 & -3.37 & 1.73 & 1.12 & .27 \\
\hline Phoneme elision & 3.38 & 3.4 & 1.56 & 1.67 & -1.48 & .15 \\
\hline Phoneme blending & 6.92 & 4.64 & 5.22 & 3.63 & -0.92 & .37 \\
\hline
\end{tabular}

Means and $S D$ s for age (years), global IQ, word, nonword, and text reading speed and accuracy ( $Z$ scores), phoneme elision, and phoneme blending (number of errors on 20 items) in the two DD groups.

The importance of a speed deficit is well established in shallow orthographies (e.g., Wimmer \& Mayringer, 2002; Tressoldi, Stella, \& Faggella, 2001; Wimmer, 1993).

Phonological skills were measured in dyslexic children by using the number of errors in two phoneme awareness tasks. The "phoneme elision" task required deletion of the first two phonemes in a list of 20 orally presented Italian words (e.g., "EUROPA" to "ROPA"), whereas the "phoneme blending" task required to put together sounds spoken by the experimenter into a word (from a list of 20 Italian words; e.g., "M-A-N-O" to "MANO"). Both groups of dyslexics had impaired phonological skills. Note that performance in these tasks is near ceiling after Grade 2 in normally developing children (also see Cossu, Shankweiler, Liberman, Katz, \& Tola, 1988).

The two groups of dyslexic children were matched for chronological age, IQ, reading speed, and phonological skills. As expected, DDN - were more impaired than $\mathrm{DDN}+$ also in word reading accuracy. As recommended by Goswami (2003), we included two different control groups: (i) the chronological age (CA) group included children matched to the dyslexics for age and IQ, and (ii) the reading level (RL) group included younger children matched to the dyslexics for reading ability and IQ. All children in the control groups were recommended as normal readers by their teachers. The CA group included 16 typically developing children (age range $=8-12$ years, mean age $=10.98$ years, $S D=1.12$ years; 5 males and 11 females) at or above the norm on an age-standardized Italian reading test (word reading: accuracy $=+0.24 Z$ score, $S D=0.5$, and speed $=+0.72 Z$ score, $S D=0.71$; Sartori et al., 1995). Their mean performance at the Vocabulary and Block Design WISC-R (Wechsler, 1986) subtests was 12.8 standard score $(S D=2.4)$ and 12.5 standard score $(S D=3.3)$, respectively. The RL group included 15 typically developing children (age range $=6-9$ years, mean age $=7.78$ years, $S D=1.12$ years; 8 males and 7 females) matched to DDN - for reading ability, measured by an efficiency index calculated as the ratio between word reading speed in seconds and accuracy rate. Mean efficiency was $310(S D=156)$ for DDN - and $244(S D=160)$ for $\mathrm{RL}, t(26)=1.1, p=.28$. Mean performance of the RL group in the Vocabulary and Block Design WISC-R (Wechsler, 1986) subtests was 11.9 standard score $(S D=3.2)$ and 11.1 standard score $(S D=3.3)$, respectively. All participants' parents gave informed consent.

\section{Apparatus}

Testing was carried out in a dimly lit (luminance of $1.5 \mathrm{~cd} / \mathrm{m}^{2}$ ) and quiet room (approximately $50 \mathrm{~dB}$ sound pression level [SPL]). Participants sat in front of a computer screen (background luminance of $0.5 \mathrm{~cd} / \mathrm{m}^{2}$ ), with their head positioned on a headrest so that the eye-screen distance was $40 \mathrm{~cm}$. The fixation point consisted of a cross ( $1^{\circ}$ of visual angle) appearing at the center of the screen.

\section{Visual Spatial Attention Task}

Two circles $\left(2.5^{\circ}\right)$ were presented peripherally $\left(8^{\circ}\right.$ of eccentricity), one to the left and one to the right of the fixation point. The peripheral cue consisted of the offset (40 msec in duration) and then the onset of one of the circles. A dot $\left(0.5^{\circ}\right)$ in the center of one of the two circles was the target stimulus (40 $\mathrm{msec}$ in duration). Stimuli were white on a black background and had a luminance of $24 \mathrm{~cd} / \mathrm{m}^{2}$ (see Figure 1A).

\section{Auditory Spatial Attention Task}

The sounds were presented over headphones (Sennheiser HD270, Germany). The auditory spatial cue consisted of single pure tone of $1000 \mathrm{~Hz}$ presented to either the left or the right ear. The cue was followed by a target sound, which consisted of a single pure tone of $800 \mathrm{~Hz}$ presented 
to the same or the opposite ear. The cue and the target sounds were presented for $40 \mathrm{msec}$ at approximately 65 dB SPL (see Figure 1B).

\section{Procedure}

Participants were instructed to keep their eyes on the fixation point throughout the duration of the trial. Eye movements were monitored by means of a video camera system. Each trial started with the onset of the fixation point. The display contained the two lateral circles only in the visual spatial attention task. The spatial cue was presented after $500 \mathrm{msec}$ in either the left or the right location (i.e., one of the two lateral circles for visual task or one of the two ears for the auditory task). The cue was followed by the target at one of two cue-target SOAs (100 or $250 \mathrm{msec}$ ).

On response trials, the probability that the target would appear in the cued location (cued trial) or in the other location (uncued trial) was 50\% (cue location was nonpredictive of target location). In contrast, on catch trials the target was not presented and participants did not have to respond. Catch trials were intermingled with response trials. Participants were instructed to react as quickly as possible to the onset of the visual and the auditory targets by pressing the spacebar on the computer keyboard. Both simple RTs and error rates were recorded by the computer. The maximum time allowed to respond was $1500 \mathrm{msec}$. The intertrial interval was $1000 \mathrm{msec}$. The experimental session consisted of 160 trials divided into two blocks of 80 trials each. Trials were distributed as follows: 32 valid trials (16 for each cue-target delay), 32 invalid trials (16 for each cue-target delay), and 16 catch trials (20\% of total trials). The administration sequence of the two attention tasks (visual vs. auditory) was counterbalanced across subjects.

\section{Data Analysis}

Errors in the visual attention task, that is, responses on catch trials and missed responses, were less than $4 \%$ and were not analyzed. Outliers were defined as RTs faster than 150 msec or more than 2.5 SDs above the mean and were excluded from the data sets before the analyses were carried out. This resulted in the removal of approximately $2 \%$ of all observations. Trials discarded because of eye movements were about $5 \%$ of the total. Errors in the auditory attention task were less than $3 \%$ and were not analyzed. Outliers were excluded from the data before the analyses were carried out. This resulted in the removal of approximately $3 \%$ of all observations. Trials discarded because of eye movements were about $3 \%$ of total trials.

\section{RESULTS}

\section{Multisensory Spatial Attention: Group Analyses}

Mean correct detection RTs were analyzed with a mixed ANOVA that had sensory modality (visual vs. auditory task), target condition (cued vs. uncued), and cue-target SOA (100 vs. $250 \mathrm{msec}$ ) as within-subject factors and group (DDN-, $\mathrm{DDN}+, \mathrm{CA}$, and RL controls) as between-subject factor.

The main effect of SOA was significant, $F(1,49)=54.58$, $p<.0001$; RTs were faster at 250-msec SOA (434 msec) than at 100-msec SOA (457 msec; i.e., a warning effect of $27 \mathrm{msec}$ ). The target condition main effect was significant, $F(1,49)=27.69, p<.0001$; RTs were faster in the cued condition ( $438 \mathrm{msec}$ ) than in the uncued condition (452 msec; i.e., a cueing effect of $14 \mathrm{msec}$ ). The group main effect was not significant, $F(3,49)=2.46, p=.074$.

The Sensory Modality $\times$ SOA interaction was significant, $F(1,49)=31.76, p<.0001$, indicating that the warning effect was larger in the auditory modality than in the visual modality (37 vs. 9 msec, respectively). The Sensory Modality $\times$ Group interaction was also significant, $F(3,49)=11.55, p<.0001$, indicating that in RL controls the RTs to auditory stimuli were slower than to visual stimuli (i.e., an RT difference of $67 \mathrm{msec}$ ). Crucially, the Group $\times$ SOA $\times$ Target Condition interaction was significant, $F(2,49)=17.28, p<.0001$ (see Figure 2 ), indicating that the time course of attention orienting varied across groups. Planned contrasts (with Bonferroni correction yielding a critical $p$ value of .006) showed that the cueing effect was significant at the 100-msec SOA in $\mathrm{DDN}+(21 \mathrm{msec}), F(1,49)=8.47, p=.005$, CA controls (22 msec), $F(1,49)=17.01, p=.0001$, and RL controls (28 msec), $F(1,49)=27.16, p<.0001$, whereas it was not significant in DDN $-(-4 \mathrm{msec}, F<1)$. In contrast, only DDN - showed a significant cueing effect at the 250-msec SOA: $34 \mathrm{msec}, F(1,49)=24.06, p<.0001$; CA, $F<1$; RL, $F<1 ; \mathrm{DDN}+, F(1,49)=1.43, p=.24$. The Group $\times$ Sensory Modality $\times$ SOA $\times$ Target Condition interaction was not significant $(F<0.02)$, showing that the time courses of attention orienting in the different groups were not modulated by the sensory modality.

Notably, the critical three-way interaction Group $\times$ SOA $\times$ Target Condition was significant, $F(3,39)=14.09$, $p<.0001$, even when chronological age and word reading accuracy were included as covariates in the ANOVA. Thus, the sluggish multisensory ESA is a specific feature of DDNand it cannot be accounted for by differences in age or literacy skills (or degree of severity of the reading deficit).

To further investigate the time course of ESA, we directly compared the cueing effect at two different cuetarget SOAs. The RT difference between uncued and cued conditions (i.e., cueing effect) was submitted to a mixed ANOVA in which the two within-subjects factors were sensory modality (visual vs. auditory) and cue-target SOA (100 vs. $250 \mathrm{msec}$ ). The between-subjects factor was group (DDN-, DDN+, CA, and RL controls). Importantly, only the group $\times$ SOA interaction was significant, $F(3,48)=17.28, p<.0001$. The crossover interaction (see Figure 3A) clearly indicates that the cueing effect at the two different SOAs varied in opposite directions for DDN- versus all other groups (for both visual and auditory tasks; see Figure 3B and C). 
Figure 2. Mean RT and $S E$ s as a function of group (DDN-, $\mathrm{DDN}+$, and controls), target condition (cued vs. uncued), and cue-target SOA (100 vs. $250 \mathrm{msec}$ ) The data are averaged across sensory modality.

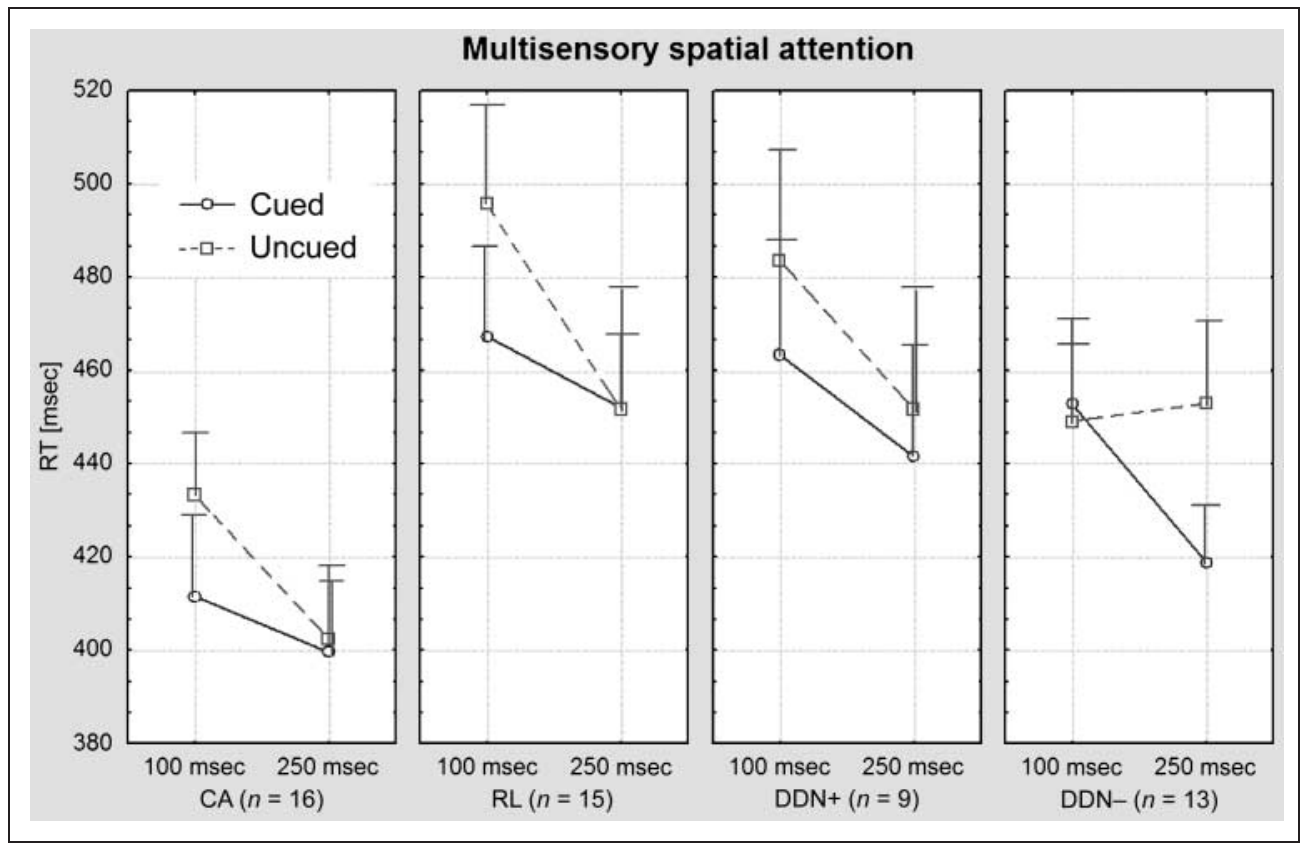

Post hoc comparisons (Newman-Keuls) showed that cueing effects at 100-msec SOA were different between DDN - $(-4 \mathrm{msec})$ and DDN $+(20 \mathrm{msec} ; p=.034)$, between DDN - and CA (22 msec; $p=.008)$, and between DDN - and RL controls (28 msec; $p<.001)$, whereas they did not differ between DDN + and CA controls $(p=.87)$, between DDN + and RL controls $(p=.57)$, and between CA and RL controls $(p=.32)$. In the same vein, the cueing effects at 250 -msec SOA were different between DDN- (34 msec) and CA controls (3 msec; $p<$ $.001)$, between DDN - and RL $(-2 \mathrm{msec} ; p<.001)$, and between DDN - and DDN + (10 msec; $p=.032)$, whereas they did not differ between DDN + and CA controls $(p=$ .36), between DDN+ and RL controls ( $p=.37$ ), and between CA and RL controls $(p=.61)$. In summary, the data revealed a marked offset of the time course of attention in DDN-, which indicates a sluggish multisensory ESA.

\section{Multisensory Spatial Attention: Individual Data}

Although children in the DDN - group showed a sluggish multisensory ESA at the group level, it is important to establish how reliable is this abnormal pattern at the level of individual dyslexics. We used the difference between cueing effects at 250- and 100-msec SOAs (across visual and auditory modality) to index the speed of attention orienting. This index is referred to as "rapid orienting index" (ROI) because positive values indicate that attention is rapidly oriented to the cued location at the short SOA, whereas negative values indicate a slower orienting that becomes more prominent at the longer SOA. Most notably, all DDN - children (100\%) were at least $1 S D$ below the mean of CA controls (mean ROI $=18.75, S D=$
14.63). Eleven out $13 \mathrm{DDN}-$ children (85\%) were at least $1 S D$ below the mean of RL controls (mean ROI $=28.7$, $S D=38.23)$ as well as of DDN + (mean ROI $=10.33, S D=$ 18.4; see Figure 4). It is common practice to define deficient performance as one falling more than $1 S D$ below the control mean (e.g., Ziegler, Pech-Georgel, George, Alario, \& Lorenzi, 2005).

We obtained similar results using the more stringent test of comparing the individual ROI of each DDN- child to the different control groups (CA, RL, and DDN+) following the statistical procedure of Crawford and Garthwaite (2007). The number of significantly impaired DDN- children was 11/13 (85\%) in comparison to CA controls, 10/13 (77\%) in comparison to RL controls, and $11 / 13$ (85\%) in comparison to DDN+. It is worth noting that no DDN+ children showed an abnormal ROI in comparison to both CA and RL controls.

\section{The Relationship between Multisensory Spatial Attention and Phonological Decoding in Dyslexic Children}

Having established that DDN- shows a sluggish ESA, we investigated the relationship between individual measures of ROI and reading performance across our entire sample of dyslexic children $(n=22)$. Correlations between ROI, age, IQ, phonological skills (mean between phoneme elision and phoneme blending), word, and nonword reading accuracy (on the standardized lists) in the 22 dyslexic children are shown in Table 2. As expected, phonological skills significantly correlated with both word reading $(r=.57, p<.05)$ and nonword reading accuracy $(r=.51, p<.05) .^{2}$ More interestingly, ROI significantly 
correlated with both word reading $(r=.45, p<.05)$ and nonword reading accuracy $(r=.68, p<.01)$. The correlation between attention orienting and nonword reading (but not word reading) remained significant when ROI was separated between visual $(r=.43, p<.05)$ and auditory $(r=.42, p<.05)$ modalities. Finally, we found a significant correlation $(r=.42, p<.005)$ between ROI and word reading across the entire sample of children $(N=$ 53 , i.e., $22 \mathrm{DD}+31$ controls; nonword reading performance was not available for controls).
To determine predictive relationships between the time course of multisensory ESA and reading performance in a more stringent way, we computed a four-step fixed-entry multiple regression analysis on the individual data of the dyslexic children to control for the effects of age, IQ, and phonological skills. The latter were indexed by the mean of the number of errors in the phoneme elision and phoneme blending tasks (for details, see Methods section). The dependent variable was nonword reading accuracy, and the predictors entered at the four steps were (i) age, (ii) IQ,
Figure 3. Mean of cueing effect (i.e., uncued-cued RT differences) and SEs as a function of cue-target SOA (100 vs. $250 \mathrm{msec}$ ) and group (CA and RL controls, DDN+, and $\mathrm{DDN}-$ ). Multisensory (averaged across sensory modality) cueing effect is shown in panel A, whereas visual and auditory cueing effects are shown in panels B and $\mathrm{C}$, respectively.

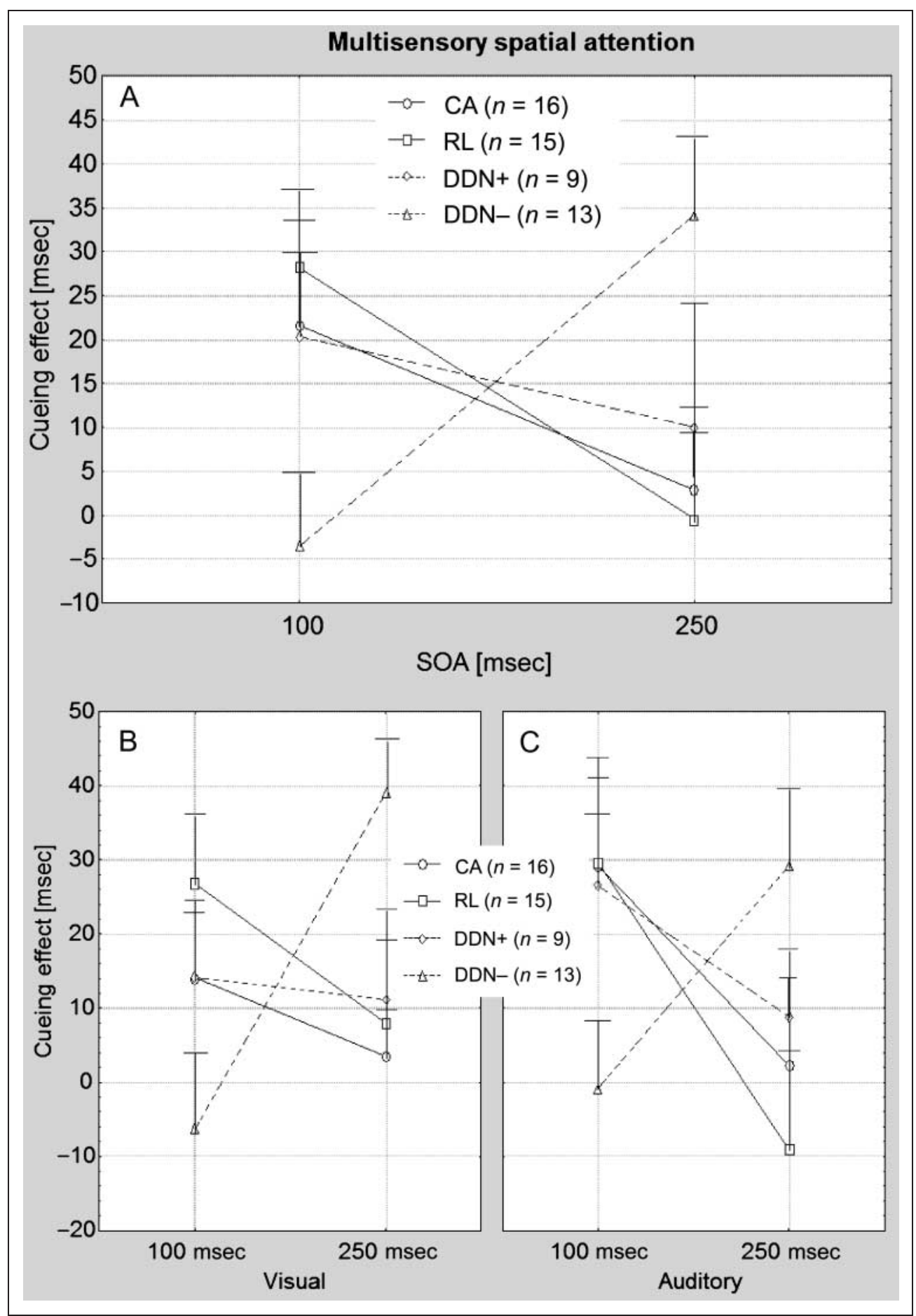




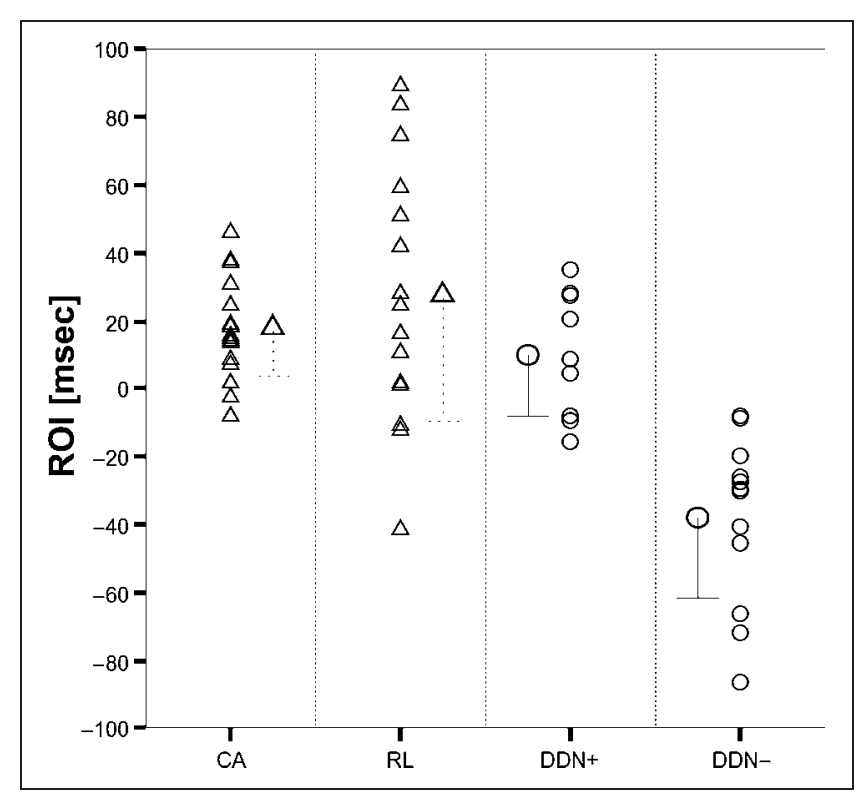

Figure 4. Individual values of ROI plotted as a function of group $(\mathrm{CA}=$ chronological age controls; $\mathrm{RL}=$ reading level controls; $\mathrm{DDN}+=$ dyslexics with near-normal nonword reading accuracy; DDN $-=$ dyslexics with poor nonword reading accuracy). ROI is indexed by the difference (msec) between the cueing effects at the 250- and the 100-msec SOAs (averaged across sensory modality). Mean and $-1 S D$ bar are also shown for each group.

(iii) phonological skills, and (iv) ROI, respectively. The measure of phonological skills entered third accounted for $27 \%(p<.05)$ of unique variance. More importantly, the ROI measure entered last accounted for 31.5\% ( $p<$ .005 ) of unique variance in nonword reading accuracy (see Table 3 and Figure 5). The same multiple regression analysis using word reading accuracy as the dependent variable yielded $27.8 \%(p<.05)$ of unique variance accounted for by phonological skills (entered third) and $12.3 \%$ (although not reaching significance; $p=.07$ ) of unique variance accounted for by the ROI measure entered last (see Table 3).

One possible concern regarding the regression analyses reported above is that the ratio between sample size and number of predictors is close to the minimum for being statistically meaningful. We therefore repeated the analy-
Table 3. Multiple Regression Analyses

\begin{tabular}{lcccccc}
\hline & \multicolumn{2}{c}{ Nonword } & & \multicolumn{2}{c}{ Word } \\
\cline { 2 - 3 } & $R^{2}$ Change & $p$ & & $R^{2}$ Change & $p$ \\
\hline Step 1: Age & .001 & $n s$ & .040 & $n s$ \\
Step 2: IQ & .004 & $n s$ & .012 & $n s$ \\
Step 3: Phonological & .27 & $<.05$ & .278 & $<.05$ \\
$\quad$ skills & & & & & \\
Step 4: ROI & .315 & $<.005$ & .123 & .07 \\
\hline
\end{tabular}

Percentage of unique variance in nonword and word reading accuracy of all dyslexic children $(n=22)$ accounted for by the different predictors (age, IQ, phonological skills, and ROI) in the four-step fixed-entry multiple regression analysis.

ses using only two predictor variables (i.e., phonological skills and ROI) to obtain a more appropriate ratio. When regressed onto nonword reading accuracy, phonological skills accounted for 26.5\% ( $p<.05)$ of unique variance, and ROI (entered last) accounted for 32.1\% $(p<.001)$ of unique variance. The regression on word reading accuracy yielded $32.1 \%(p<.01)$ of unique variance for phonological skills and 10\% (again not reaching significance; $p=.08$ ) of unique variance for the ROI measure entered last.

Finally, to confirm the specific relationship between multisensory ESA and phonological decoding, we computed a two-step fixed-entry multiple regression analysis in which word reading accuracy (which is also an index of literacy skills) was entered before ROI. Word reading entered first accounted for 66\% ( $p<.0001)$ of unique variance. Nevertheless, ROI entered last accounted for $13 \%(p<.005)$ of unique variance in nonword reading accuracy, demonstrating the specific role of multisensory ESA in phonological decoding.

\section{DISCUSSION}

The results of the present study clearly demonstrate that only poor phonological decoders (DDN-) have a temporal deficit of multisensory ESA. In CA- and RL-matched

Table 2. Correlations between ROI, Age, Global IQ, Phonological Skills (i.e., Mean between Phoneme Elision and Phoneme Blending), Word, and Nonword Reading Accuracy in Dyslexic Children $(n=22)$

\begin{tabular}{|c|c|c|c|c|c|c|}
\hline & $R O I$ & Age & $I Q$ & Phonological Skills & Word & Nonword \\
\hline Age & .01 & - & & & & \\
\hline IQ & -.21 & -.49 & - & & & \\
\hline Phonological skills & .26 & -.36 & .21 & - & & \\
\hline Word & .45 & .20 & .19 & .57 & - & \\
\hline Nonword & .68 & .09 & -.01 & .51 & .81 & - \\
\hline
\end{tabular}

Correlations in bold are significant at $p<.05$. 


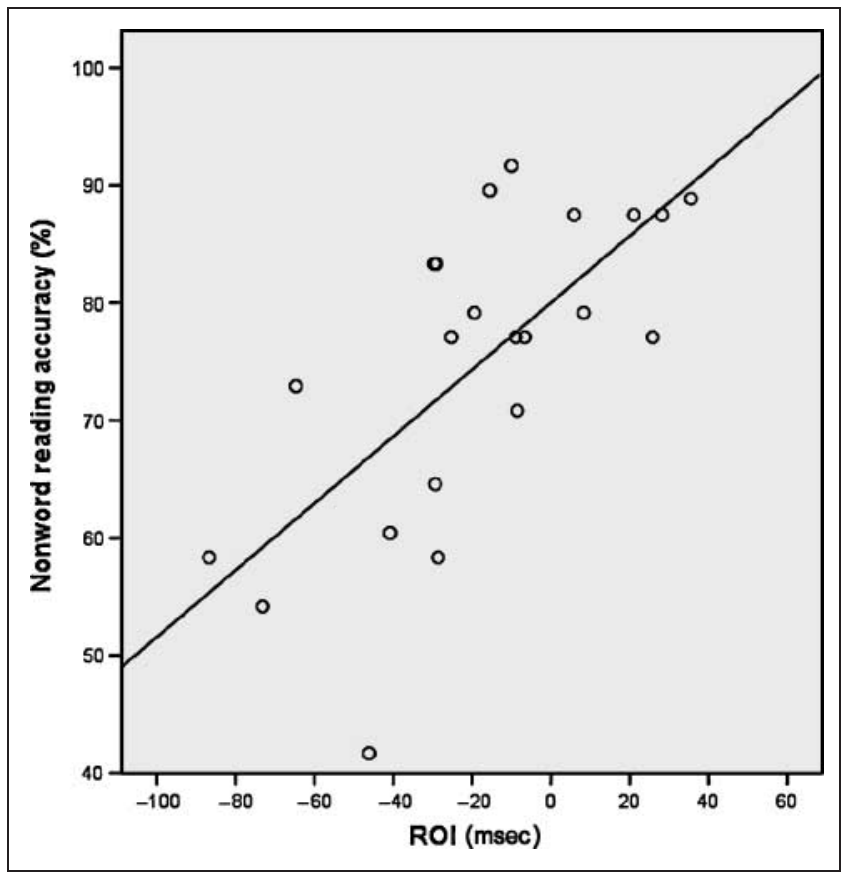

Figure 5. Scatter plot of the relationship between time course of multisensory spatial attention (ROI) and nonword reading accuracy across our entire sample of dyslexic children $(n=22)$.

controls, spatial attention was rapidly engaged onto both visual and auditory stimuli. The attentional cueing effect was present at the shortest cue-target SOA (i.e., $100 \mathrm{msec}$ ), whereas it disappeared at the longer SOA (i.e., $250 \mathrm{msec}$ ), as predicted by automatic capture theories (for a review, see Klein, 2000). In contrast, DDN - children selectively showed a slower multisensory attentional orienting: The cueing effect was not present at the short SOA whereas it was present at longer SOA, as predicted by the "sluggish attentional shifting” theory (Hari \& Renvall, 2001). This deficit was present also in comparison to dyslexics with accurate but slow nonword decoding (DDN+).

Importantly, the results obtained in the between-group analyses cannot be attributed to the presence of a few (and perhaps peculiar) dyslexic children in the DDNgroup but were fully confirmed by the analyses at the level of individual cases. Indeed, multisensory attentional orienting deficits were present in all poor phonological decoders (100\%) in comparison to CA controls $(85 \%$ in comparison to RL controls). Moreover, the orienting deficit was not present in any of the dyslexic children who were accurate decoders. Thus, our attention orienting index allowed us to accurately discriminate between poor phonological decoders and controls.

Overall, our results suggest that a multisensory deficit of attention is a core deficit in dyslexics characterized by poor (i.e., inaccurate) phonological decoding (the most frequent pattern even in Italian dyslexics; see Facoetti et al., 2006). This conclusion was supported by the finding that individual differences in the orienting of multisensory attention were predictive of reading performance even after controlling for age, IQ, and phonological skills. It is important to stress that the predictive relationship between attention and reading skills held across the entire sample of dyslexics, that is, independently of any a priori classification or subtyping of the dyslexic children. Thus, regardless of whether children in the DDN+ group (i.e., slow but accurate) constitute a specific subtype in shallow orthographies (e.g., Wimmer, 1993) or they have partly compensated their reading deficit, ${ }^{3}$ rapid and efficient orienting of spatial attention seems to play an important role in phonological decoding.

Our findings are consistent with the results of Facoetti et al. (2006) and with the predictions of the CDP+ computational model of reading aloud (Perry et al., 2007). Indeed, $\mathrm{CDP}+$ assumes that focused spatial attention is specifically involved in the sublexical spelling-to-sound mapping process (i.e., the sublexical route). Accordingly, our multisensory orienting index was a better predictor of nonword reading compared with word reading. Moreover, the ROI accounted for $13 \%$ of unique variance in nonword reading accuracy even when literacy skills (i.e., word reading accuracy) were partialled out. Clearly, these results are inconsistent with the hypothesis that dyslexia is an exclusively phonological deficit that sometimes co-occurs with a more general sensorimotor syndrome (Ramus, 2003; e.g., visual spatial-parietal and/or motor-cerebellar dysfunction).

The present link between deficits in orienting spatial attention and impaired phonological decoding is consistent with the results of recent studies on adult dyslexics that used visual search paradigms (Jones et al., 2008; Roach \& Hogben, 2007; Buchholz \& McKone, 2004). Notably, the fact that the latter studies involved English participants rules out the possibility that our findings are specific to highly transparent orthographies like Italian. In addition, neuropsychological studies on patients with neglect dyslexia suggest an interaction between the attentional system and the different reading routes. Hemispatial neglect severely affects phonological decoding but has less effect on lexical-semantic processing, suggesting that reading unfamiliar words and nonwords depends on focused visual attention to control the sequence of parts of the input string to be admitted to the spelling-to-sound translation process (Ladavas et al., 1997; Sieroff et al., 1988).

Our contention that a multisensory attentional deficit is a crucial component of impaired phonological decoding in DD must be also discussed in relation to other alternative explanations of our findings. Specifically, we discuss (i) the direction of the link between attention and reading skills, (ii) the possible role of a temporal processing deficit, and (iii) the possible role of a noise exclusion deficit.

\section{The Relationship between Attention and Reading: Which Direction?}

The issue of whether visual and auditory deficits are causally linked to reading disorders in dyslexic children has been hotly disputed (e.g., Ramus, 2003). In particular, 
it might be argued that the attentional deficit is a consequence of the reading difficulties that characterize DD. Evidence against the latter interpretation should be found in the comparison of dyslexics to control children that are matched for reading level. In the present study, sluggish spatial attention was found in poor phonological decoders in comparison not only to CA but also to RL controls. This finding strongly suggests that attention orienting deficits are causally linked to the reading disorder rather than the converse. The causal hypothesis should be further tested in training and/or longitudinal studies (for discussion, see Goswami, 2003). To this aim, it is worth noting that the reading performance of dyslexic children has been shown to improve following a specific training for visuospatial attention (e.g., Facoetti, Lorusso, Paganoni, Umiltà, \& Mascetti, 2003; Geiger, Lettvin, \& Fanhle, 1994). Moreover, longitudinal studies have shown that visual attention, in addition to syllable awareness, is one of the most important predictors of early reading abilities (e.g., Ferretti, Mazzotti, \& Brizzolara, 2008; Plaza \& Cohen, 2006).

\section{The Role of Temporal Processing Deficits}

A number of authors have suggested that the core deficit in dyslexia is related to a reduced speed of visual and auditory processing (i.e., a temporal processing deficit; for reviews, see Tallal, 2004; Farmer \& Klein, 1995). One might therefore ask whether the sluggish attentional orienting could be determined by the nature of our paradigm and in particular by the relative timing of perceptual events. However, the time duration of visual and auditory cues (40 msec) as well as of targets (40 msec) does not appear to provide a satisfactory explanation of the attentional deficit because attentional orienting was present in poor decoders at the longest cue-target SOA (i.e., $250 \mathrm{msec}$ ). Instead, the deficit is dependent on the interval between cue and target stimuli (i.e., the time course of spatial attentional orienting).

Conversely, the finding that auditory spatial attention is impaired in poor phonological decoders raises the question of whether deficits in the processing of rapid sound sequences could be a consequence of sluggish attention (Facoetti et al., 2005; Renvall \& Hari, 2002; Helenius, Uutela, \& Hari, 1999). Hari and Renvall (2001) suggested that sluggish attention shifting would prolong sensory input chunks, which would lead to degraded representation of auditory objects.

\section{The Role of Noise Exclusion Deficits}

Detection of a brief visual or auditory signal rapidly followed by noise (backward masking) is impaired in dyslexic children (e.g., Montgomery, Morris, Sevcik, \& Clarkson, 2005; Di Lollo, Hanson, \& McIntyre, 1983). Interestingly, auditory backward masking predicts not only nonword reading abilities but also phonological skills (Montgomery et al., 2005). Impaired identification of the first of two rapidly presented visual objects ("informational" or attentional masking) was recently shown in dyslexic children and was correlated with nonword reading ability (Facoetti, Ruffino, Peru, Paganoni, \& Chelazzi, 2008). Dyslexics are also disturbed by spatial masking: Perception of visual and auditory objects is impaired in dyslexic children when flanked by lateral noise (Geiger et al., 2008). Moreover, the lateral interference between adjacent letters (i.e., crowding; for a review, see Levi, 2008) is abnormal in dyslexia (Spinelli, De Luca, Judica, \& Zoccolotti, 2002; Atkinson, 1991). In particular, dyslexics seem to have more crowding near the fovea than normal readers (Lorusso et al., 2004; Geiger \& Lettvin, 1987). Recent studies show that crowding represents a limit for reading in skilled adults (e.g., Pelli et al., 2007).

Thus, both temporal (Facoetti et al., 2008; Montgomery et al., 2005; Di Lollo et al., 1983) and spatial (e.g., Geiger et al., 2008; Sperling et al., 2005; Geiger \& Lettvin, 1987) multisensory processing windows in which noise interferes with the signal appear to be broader in dyslexics in comparison to normally reading children. This has been recently referred to as a perceptual noise exclusion deficit (Sperling et al., 2005). Accordingly, Ziegler et al. (2005) showed that children with SLI have poorer-than-normal phoneme identification only when measured in ecologically valid conditions of stationary or fluctuating masking noise. Speech identification in noise was strongly correlated to SLI children's nonword reading skills (Ziegler et al., 2005).

We suggest that a possible cause of dyslexics' larger visual and auditory "informational" masking (i.e., multisensory perceptual noise exclusion deficit) could be their sluggish spatial attention (see also Hari \& Renvall, 2001). Indeed, spatial attention modulates perceptual noise exclusion, optimizing the perceptual filter so that signal is processed and noise is excluded (e.g., Dosher \& Lu, 2000). On the other hand, it seems unlikely that a noise exclusion deficit would cause the sluggish orienting of spatial attention shown by our poor phonological decoders because the cueing task used in the present study does not involve noisy stimuli.

\section{Neurobiological Substrate of Multisensory Attentional Deficits}

The sluggish, abnormal pattern of attentional orienting found in the present study points to a possible dysfunction of the right TPJ as its neuroanatomical correlate. TPJ is crucially involved in the control of multisensory attention in humans (Downar, Crawley, Mikulis, \& Davis, 2000) and is part of a right-hemisphere cortical network (i.e., TPJ and ventral frontal cortex) devoted to stimulus-driven (i.e., exogenous) orienting (Corbetta \& Shulman, 2002). In agreement with the present results, other psychophysical findings (i.e., spatial cueing task, temporal order judgment, and perception of line motion illusion) suggest that 
dyslexic children and adults suffer from a left-side "minineglect" (Facoetti, Turatto, Lorusso, \& Mascetti, 2001; Hari, Renvall, \& Tanskanen, 2001). In addition, neurological patients with right TPJ damage show a severe loss in the perception of apparent motion in their "good" right visual field (Battelli et al., 2001). This deficit is probably due to a bilateral impairment in attention to the transient events that drive the apparent motion percept (i.e., the "when" pathway; for a review, see Battelli, Pascual-Leone, \& Cavanagh, 2007). Interestingly, this motion perception deficit is similar to that shown by phonological dyslexic children (Cestnick \& Coltheart, 1999). Moreover, the right TPJ plays a crucial role in selecting a target among interfering distractors, filtering out irrelevant information (FriedmanHill, Robertson, Desimone, \& Ungerleider, 2003).

A weakened or abnormal magnocellular input to the dorsal visual stream (Livingstone, Rosen, Drislane, \& Galaburda, 1991; for a review, see Boden \& Giaschi, 2007) could result in a dysfunction of TPJ. Deficits of the magnocellular system, albeit controversial (e.g., Amitay, Ben-Yehudah, Banai, \& Ahissar, 2002), could thus influence higher visual processing stages through the dorsal pathway and therefore lead to reading difficulties via attentional mechanism (for reviews, see Boden \& Giaschi, 2007; Hari \& Renvall, 2001; Vidyasagar, 1999). A recent psychophysical study showed that magnocellular-based perceptual performance (i.e., global dot motion threshold) was compromised in poor phonological decoders (Roach \& Hogben, 2007). More importantly, the same subjects showed clear visual spatial attentional impairment, showing a defective attentional facilitation when the location of the target was indicated by brief peripheral cue (Roach \& Hogben, 2007).

Although the distinction between magno- and parvocellular pathways is not typically made for the auditory system, "magno" cells exist in the medial geniculate nuclei of the auditory thalamus; moreover, these cells were found to be smaller and more disorganized in the postmortem brains of dyslexic in comparison to controls (Galaburda, Menard, \& Rosen, 1994). The bilateral auditory cortices of dyslexic adults were shown to be less reactive to acoustical changes than those of controls in a magneto-encephalographic study, suggesting an insufficient triggering of stimulus-driven auditory attention (Renvall \& Hari, 2002). Similarly, SLI children (with comorbid DD) show a marked and specific deficit in the neural mechanisms of auditory spatial attention that affects the earliest stages of sensory processing (Stevens et al., 2006).

The important role of right TPJ is shown by a recent fMRI study of reading acquisition in normally developing children (Turkeltaub et al., 2003). The finding of a negative correlation between right TPJ activation and age suggests that this area could be particularly crucial for learning the mapping between visual-orthographic information and auditory-phonological representations during the early stages of reading acquisition. Moreover, right
TPJ hypoactivation has been reported in dyslexic children, even in comparison to RL controls (Hoeft et al., 2006) as well as in adult dyslexics (Grünling et al., 2004; Rumsey et al., 1997). Conversely, right TPJ showed increased activation in dyslexics after remediation (Eden et al., 2004). Finally, a significant reduction of gray matter volume in the right posterior parietal lobule has been observed in dyslexics compared with controls (Menghini et al., 2008).

In conclusion, the predictive value of multisensory attentional orienting in relation to phonological decoding skills offers a new nonlinguistic approach to early identification and remediation of DD. Moreover, sluggish multisensory orienting appears to be a sensitive behavioral marker of right TPJ dysfunction in DD.

\section{Acknowledgments}

We thank P. Paganoni for helpful discussions and T. Mazzotta for help in data collection. This work was supported by the Italian Ministry of Health to A. F. and M. M. (RC 2006 and 2007), the Italian Ministry of University and Scientific Research to A. F. (PRIN 2007) and M. Z. (PRIN 2006), and the "Amici della Pediatria" Association of Bergamo General Hospital to A. F.

Reprint requests should be sent to Andrea Facoetti or Marco Zorzi, Dipartimento di Psicologia Generale, Via Venezia, 8, 35131 Padova, Italy, or via e-mail: andreafacoetti@unipd.it or marco.zorzi@unipd.it.

\section{Notes}

1. Note that inaccurate decoding is the most frequent pattern in Italian dyslexics. In the study of Facoetti et al. (2006), 70\% of the dyslexics (in a sample of $n=33$ ) showed impaired nonword reading.

2. ROI did not correlate with the overall index of phonological skills (see Table 2). However, the correlation between ROI and phoneme elision fell just short of significance $(r=.32, p=.08)$. This suggests that more sensitive phonological segmentation tasks might show a higher correlation with our index of multisensory spatial attention.

3. It is worth noting that the fluency deficit has been attributed - at least in a regular orthography like Italian-to a difficulty in the buildup of orthographic representations for words or parts of words larger than graphemes (e.g., syllables, morphemes; e.g., Tressoldi, Vio, \& Iozzino, 2007).

\section{REFERENCES}

American Psychiatric Association. (1994). Diagnostic and statistical manual of mental disorders (4th ed.). Washington, DC: APA.

Amitay, S., Ben-Yehudah, G., Banai, K., \& Ahissar, M. (2002). Disabled readers suffer from visual and auditory impairments but not from a specific magnocellular deficit. Brain, 125, 2272-2285.

Ans, B., Carbonnel, S., \& Valdois, S. (1998). A connectionist multiple-trace memory model for polysyllabic word reading. Psychological Review, 105, 678-723.

Asbjørnsen, A. E., \& Bryden, M. P. (1998). Auditory attentional shifts in reading-disabled students: Quantification of attentional effectiveness by the Attentional Shift Index. Neuropsychologia, 36, 143-148. 
Atkinson, J. (1991). Review of human visual development: Crowding and dyslexia. In J. Stein (Ed.), Vision and visual dyslexia (pp. 44-57). Boca Raton, FL: CRC Press.

Auclair, L., \& Sieroff, E. (2002). Attentional cueing effect in the identification of words and pseudowords of different length. Quarterly Journal of Experimental Psychology, 55, 445-463.

Battelli, L., Cavanagh, P., Intriligator, J., Tramo, M. J., Henaff, M. A., Michel, F., et al. (2001). Unilateral right parietal damage leads to bilateral deficit for high level motion. Neuron, 32, 985-995.

Battelli, L., Pascual-Leone, A., \& Cavanagh, P. (2007). The "when" pathway of the right parietal lobe. Trends in Cognitive Sciences, 11, 204-210.

Boden, C., \& Giaschi, D. (2007). M-stream deficits and reading-related visual processes in developmental dyslexia. Psychological Bulletin, 133, 346-366.

Bonato, M., Priftis, K., Marenzi, R., \& Zorzi, M. (2009). Normal and impaired reflexive orienting of attention after central nonpredictive cues. Journal of Cognitive Neuroscience, 21, 745-759.

Bosse, M. L., Tainturier, M. J., \& Valdois, S. (2007). Developmental dyslexia: The visual attention span deficit hypothesis. Cognition, 104, 198-230.

Buchholz, J., \& McKone, E. (2004). Adults with dyslexia show deficits on spatial frequency doubling and visual attention tasks. Dyslexia, 10, 24-43.

Carrasco, M., Williams, P., \& Yeshurum, Y. (2002). Covert attention increases spatial resolution with or without masks: Support for signal enhancement. Journal of Vision, 2, 467-479.

Castles, A., \& Coltheart, M. (1993). Varieties of developmental dyslexia. Cognition, 47, 148-180.

Cestnick, L., \& Coltheart, M. (1999). The relationship between language-processing and visual-processing deficit in developmental dyslexia. Cognition, 71, 231-255.

Coltheart, M., Rastle, K., Perry, C., Langdon, R., \& Ziegler, J. (2001). The DRC model: A model of visual word recognition and reading aloud. Psychological Review, 108, 204-258.

Corbetta, M., \& Shulman, G. L. (2002). Control of goal-directed and stimulus-driven attention in the brain. Nature Reviews Neuroscience, 3, 201-215.

Cornoldi, C., Colpo, G., \& Gruppo, M. T. (1981). Prove di Lettura MT. Firenze, Italy: (O.S.) Organizzazioni Speciali.

Cossu, G., Shankweiler, D., Liberman, I. Y., Katz, L. E., \& Tola, G. (1988). Awareness of phonological segments and reading ability in Italian children. Applied Psycholinguistics, 9, 1-16.

Crawford, J. R., \& Garthwaite, P. H. (2007). Comparison of a single case to a control or normative sample in neuropsychology: Development of a Bayesian approach. Cognitive Neuropsychology, 24, 343-372.

Di Lollo, V., Hanson, D., \& McIntyre, J. S. (1983). Initial stages of visual information processing in dyslexia. Journal of Experimental Psychology: Human Perception and Performance, 6, 623-935.

Dosher, B. A., \& Lu, Z. L. (2000). Noise exclusion in spatial attention. Psychological Science, 11, 139-146.

Downar, J., Crawley, A. P., Mikulis, D. J., \& Davis, K. D. (2000) A multimodal cortical network for the detection of changes in the sensory environment. Nature Neuroscience, 3, $277-283$.

Eden, G. F., Jones, K. M., Cappell, K., Gareau, L., Wood, F. B., Zeffiro, T. A., et al. (2004). Neural changes following remediation in adult developmental dyslexia. Neuron, 44, 411-422.

Eden, G. F., \& Zeffiro, T. A. (1998). Neural systems affected in developmental dyslexia revealed by functional neuroimaging. Neuron, 21, 279-282.
Facoetti, A., Lorusso, M. L., Cattaneo, C., Galli, R., \& Molteni, M. (2005). Visual and auditory attentional capture are both sluggish in children with developmental dyslexia. Acta Neurobiologiae Experimentalis, 65, 61-72.

Facoetti, A., Lorusso, M. L., Paganoni, P., Umiltà, C., \& Mascetti, G. G. (2003). The role of visuospatial attention in developmental dyslexia: Evidence from a rehabilitation study. Cognitive Brain Research, 15, 154-164.

Facoetti, A., Ruffino, M., Peru, A., Paganoni, P., \& Chelazzi, L. (2008). Sluggish engagement and disengagement of non-spatial attention in dyslexic children. Cortex, 44 , $1221-1233$.

Facoetti, A., Turatto, M., Lorusso, M. L., \& Mascetti, G. G. (2001). Orienting of visual attention in dyslexia: Evidence for asymmetric hemispheric control of attention. Experimental Brain Research, 138, 46-53.

Facoetti, A., Zorzi, M., Cestnick, L., Lorusso, M. L., Molteni, M., Paganoni, P., et al. (2006). The relationship between visuo-spatial attention and nonword reading in developmental dyslexia. Cognitive Neuropsychology, 23, 841-855.

Farmer, M. E., \& Klein, R. M. (1995). The evidence for a temporal processing deficit-linked to dyslexia. Psychonomic Bulletin \& Review, 2, 469-493.

Ferretti, G., Mazzotti, S., \& Brizzolara, D. (2008). Visual scanning and reading ability in normal and dyslexic children. Behavioural Neurology, 19, 87-92.

Francis, A. L., Kaganovich, N., \& Criscoll-Huber, C. (2008). Cue-specific effects of categorization training on the relative weighting of acoustic cues to consonant voicing in English. Journal of the Acoustic Society of America, 124, 1234-1251.

Friedman-Hill, S. R., Robertson, L. C., Desimone, R., \& Ungerleider, L. G. (2003). Posterior parietal cortex and the filtering of distractors. Proceedings of the National Academy of Sciences, U.S.A., 100, 4263-4268.

Galaburda, A. M., Menard, M. T., \& Rosen, G. D. (1994). Evidence for aberrant auditory anatomy in developmental dyslexia. Proceedings of the National Academy of Sciences, U.S.A., 91, 8010-8013.

Geiger, G., Cattaneo, C., Galli, R., Pozzoli, U., Lorusso, M. L., Facoetti, A., et al. (2008). Wide and diffuse perceptual modes characterized dyslexics in vision and audition. Perception, 37, 1745-1764.

Geiger, G., \& Lettvin, J. Y. (1987). Peripheral vision in persons with dyslexia. New England Journal of Medicine, 316, 1238-1243.

Geiger, G., Lettvin, J. Y., \& Fanhle, M. (1994). Dyslexic children learn a new visual strategy for reading: A controlled experiment. Vision Research, 34, 1223-1233.

Gordon, P. C., Eberhardt, J. L., \& Rueckl, J. G. (1993). Attentional modulation of the phonetic significance of acoustic cues. Cognitive Psychology, 25, 1-42.

Goswami, U. (2003). Why theories about developmental dyslexia require developmental designs. Trends in Cognitive Sciences, 7, 534-540.

Goswami, U., Thomson, J., Richardson, U., Strainthorp, R., Hughes, D., Rosen, S., et al. (2000). Amplitude envelope onsets and developmental dyslexia: A new hypothesis. Proceedings of the National Academy of Sciences, U.S.A., 99, 10911-10916.

Grünling, C., Ligges, M., Huonker, R., Klingert, M., Mentzel, H. J., Rzanny, R., et al. (2004). Dyslexia: The possible benefit of multimodal integration of fMRI- and EEG-data. Journal of Neural Transmission, 111, 951-969.

Hari, R., \& Renvall, H. (2001). Impaired processing of rapid stimulus sequences in dyslexia. Trends in Cognitive Science, 5, 525-532. 
Hari, R., Renvall, H., \& Tanskanen, T. (2001). Left minineglect in dyslexic adults. Brain, 124, 1373-1380.

Harm, M. W., \& Seidenberg, M. S. (1999). Phonology, reading acquisition, and dyslexia: Insights from connectionist models. Psychological Review, 106, 491-528.

Helenius, P., Uutela, K., \& Hari, R. (1999). Auditory stream segregation in dyslexic adults. Brain, 122, 907-913.

Hoeft, F., Hernandez, A., McMillon, G., Taylor-Hill, H., Martindale, J. L., Meyler, A., et al. (2006). Neural basis of dyslexia: A comparison between dyslexic and nondyslexic children equated for reading ability. Journal of Neuroscience, 26, 10700-10708.

Hutzler, F., Ziegler, J., Perry, C., Wimmer, H., \& Zorzi, M. (2004). Do current connectionist models account for reading development in different language? Cognition, 91, 273-296

Jones, M. W., Branigan, H. P., \& Kelly, M. L. (2008). Visual deficits in developmental dyslexia: Relationships between non-linguistic visual tasks and their contribution to components of reading. Dyslexia, 14, 95-115.

Klein, R. M. (2000). Inhibition of return. Trends in Cognitive Science, 4, 138-147.

Ladavas, E., Umiltà, C., \& Mapelli, D. (1997). Lexical and semantic processing in the absence of word reading: Evidence from neglect dyslexia. Neuropsychologia, 35, $1075-1085$.

Levi, D. M. (2008). Crowding-An essential bottleneck for object recognition: A mini-review. Vision Research, 48, 635-654.

Livingstone, M. S., Rosen, G. D., Drislane, F. W., \& Galaburda, A. M. (1991). Physiological and anatomical evidence for a magnocellular defect in developmental dyslexia. Proceedings of the National Academy of Sciences, U.S.A., 88, 7943-7947.

Lorusso, M. L., Facoetti, A., Pesenti, S., Cattaneo, C., Molteni, M., \& Geiger, G. (2004). Wider recognition in peripheral vision common to different subtypes of dyslexia. Vision Research, 44, 2413-2424.

Manis, F. R., Seidemberg, M. S., Doi, L. D., McBride-Chang, C., $\&$ Petersen, A. (2000). On the bases of two subtypes of developmental dyslexia. Cognition, 58, 157-195.

McCandliss, B. D., Cohen, L., \& Dehaene, S. (2003). The visual word form area: Expertise for reading in the fusiform gyrus. Trends in Cognitive Sciences, 7, 293-299.

Menghini, D., Hagberg, G. E., Petrosini, L., Bozzali, M., Macaluso, M., Caltagirone, C., et al. (2008). Structural correlates of implicit learning deficits in subjects with developmental dyslexia. Annals of the New York Academy of Sciences, 1145, 212-221.

Montgomery, C. R., Morris, R. D., Sevcik, R. A., \& Clarkson, M. G. (2005). Auditory backward masking deficits in children with reading disabilities. Brain and Language, 95, 450-456.

Pelli, D. G., Tillman, K. A., Freeman, J., Su, M., Berger, T. D., \& Majaj, N. J. (2007). Crowding and eccentricity determine reading rate. Journal of Vision, 7, 1-36.

Perry, C., Ziegler, J. C., \& Zorzi, M. (2007). Nested incremental modeling in the development of computational theories: The CDP + model of reading aloud. Psychological Review, 114, 273-315.

Plaza, M., \& Cohen, E. (2006). The contribution of phonological awareness and visual attention in early reading and spelling. Dyslexia, 13, 67-76.

Poghosyan, V., \& Ioannides, A. A. (2008). Attention modulates earliest responses in the primary auditory and visual cortices. Neuron, 58, 802-813.

Posner, M. I. (1980). Orienting of attention. Quarterly Journal of Experimental Psychology, 32, 3-25.
Pugh, K. R., Mencl, W. E., Shaywitz, B. A., Shaywitz, S. E., Fulbright, R. K., Constable, R. T., et al. (2000). The angular gyrus in developmental dyslexia: Task-specific differences in functional connectivity within posterior cortex. Psychological Science, 11, 51-65.

Ramus, F. (2003). Developmental dyslexia: Specific phonological deficit or general sensorimotor dysfunction? Current Opinion in Neurobiology, 13, 212-218.

Renvall, A., \& Hari, R. (2002). Auditory cortical responses to speech-like stimuli in dyslexic adults. Journal of Cognitive Neuroscience, 14, 757-768.

Reynolds, J. H., \& Chelazzi, L. (2004). Attentional modulation of visual processing. Annual Review of Neuroscience, 27, 611-647.

Reynolds, M., \& Besner, D. (2006). Reading aloud is not automatic: Processing capacity is required to generate a phonological code from print. Journal of Experimental Psychology: Human Perception and Performance, 32, 1303-1323.

Roach, N. W., \& Hogben, J. H. (2007). Impaired filtering of behaviorally irrelevant visual information in dyslexia. Brain, 130, 771-785.

Rumsey, J. M., Horwitz, B., Donohue, B. C., Nace, K., Maisog, J. M., \& Andreason, P. (1997). Phonological and orthographic components of word recognition: A PET-rCBF study. Brain, 120, 739-759.

Sartori, G., Job, R., \& Tressoldi, P. E. (1995). Batteria per la Valutazione della Dislessia e della Disortografia Evolutiva. Firenze, Italy: (O.S.) Organizzazioni Speciali.

Share, D. L. (1995). Phonological recoding and self-teaching: Sine qua non of reading acquisition. Cognition, 55, $151-218$

Sieroff, E., Pollatsek, A., \& Posner, M. (1988). Recognition of visual letter strings following injury to the posterior visual spatial attention system. Cognitive Neuropsychology, 5, 427-449.

Sperling, A. J., Lu, Z. L., Manis, F. R., \& Seidemberg, M. S. (2005). Deficits in perceptual noise exclusion in developmental dyslexia. Nature Neuroscience, 8 , 862-863

Spinelli, M., De Luca, A., Judica, P., \& Zoccolotti, P. (2002). Crowding effects on word identification in developmental dyslexia. Cortex, 38, 179-200.

Sprenger-Charolles, L., Siegel, L. S., Béchennec, D., \& Serniclaes, W. (2003). Development of phonological and orthographic processing in reading aloud, in silent reading, and spelling: A four-year longitudinal study. Journal of Experimental Child Psychology, 84, 194-217.

Stevens, C., Sanders, L., \& Neville, H. (2006) Neurophysiological evidence for selective auditory attention deficits in children with specific language impairment. Brain Research, 1111, 143-152.

Tallal, P. (2004). Improving language and literacy is a matter of time. Nature Reviews Neuroscience, 5, 721-728.

Toro, J. M., Sinnett, S., \& Soto-Faraco, S. (2005). Speech segmentation by statistical learning depends on attention. Cognition, 97, B25-B34.

Tressoldi, P. E., Stella, G., \& Faggella, M. (2001). The development of reading speed in Italians with dyslexia: A longitudinal study. Journal of Learning Disabilities, 34, 67-78.

Tressoldi, P. E., Vio, C., \& Iozzino, R. (2007). Efficacy of an intervention to improve fluency in children with developmental dyslexia in a regular orthography. Journal of Learning Disabilities, 40, 203-209.

Turkeltaub, P. E., Gareau, L., Flowers, D. L., Zeffiro, T. A., \& Eden, G. F. (2003). Development of neural mechanisms for reading. Nature Neuroscience, 6, 767-773. 
Vidyasagar, T. R. (1999). A neural model of attentional spotlight: Parietal guiding the temporal. Brain Research Review, 30, 66-76.

Wechsler, D. (1986). Scala di Intelligenza Wechsler per Bambini-Riveduta. Firenze Italy: (O.S.) Organizzazioni Speciali.

Wimmer, H. (1993). Characteristics of developmental dyslexia in a regular writing system. Applied Psycholinguistics, 14, $1-33$.

Wimmer, H., \& Mayringer, H. (2002). Dysfluent reading in the absence of spelling difficulties: A specific deficit in regular orthographies. Journal of Educational Psychology, 94, 272-277.

Ziegler, J. C., \& Goswami, U. (2005). Reading acquisition, developmental dyslexia, and skilled reading across languages: A psycholinguistic grain size theory. Psychological Bulletin, 131, 3-29.

Ziegler, J. C., Pech-Georgel, C., George, F., Alario, F. X., \& Lorenzi, C. (2005). Deficits in speech perception predict language learning impairment. Proceedings of the National Academy of Sciences, U.S.A., 102, 14110-14115.

Ziegler, J. C., Perry, C., Wyatt, A. M., Ladner, D., \& Schülte-Korne, G. (2003). Developmental dyslexia in different languages: Language-specific or universal? Journal of Experimental Child Psychology, 86, 169-193.

Zorzi, M. (2005). Computational models of reading. In G. Houghton (Ed.), Connectionist models in cognitive psychology (pp. 403-444). London, UK: Psychology Press.

Zorzi, M., Houghton, G., \& Butterworth, B. (1998a). Two routes or one in reading aloud? A connectionist dual-process model. Journal of Experimental Psychology: Human Perception and Performance, 24, 1131-1161.

Zorzi, M., Houghton, G., \& Butterworth, B. (1998b). The development of spelling-sound relationships in a model of phonological reading. Language and Cognitive Processes, 13, 337-371. 